\title{
Seismic Performance of PHC Pipe Piles Considering Soil-pile Interaction
}

\author{
Guilan Tao ${ }^{1, ~ a ~}$, Qingquan Zhou ${ }^{1, b}$ and Zhaoyang Qiao, ${ }^{1, c}$ \\ ${ }^{1}$ Hohai University, 1 Xikang Road, Nanjing, China \\ agltao@hhu.edu.cn, ${ }^{b}$ zqq920702@qq.com, ${ }^{\text {'zhaoyangqiao27@163.com }}$
}

\begin{abstract}
Keywords: PHC pipe pile; Soil-pile interaction; Seismic performance; Numerical simulation
\end{abstract} Abstract. The fibrous beam element and common node method in ABAQUS software were used to set up a finite element model of PHC pipe piles, and the seismic performance of the PHC pipe piles were studied. UCONCRETE01 constitutive model and USTEEL02 constitutive model were respectively used for the concrete and the prestressed longitudinal reinforcement in the element model of the PHC pipe piles. The soil-pile interaction was simulated by the p-y soil-spring model under cyclic loading. The influence of reinforcement ratio, buried depth, axial compression ratio, shear strength of undrained soil on the cumulative dissipating hysteretic energy and displacement ductility coefficient of the PHC pipe piles were discussed. The results show that the cumulative dissipating hysteretic energy of pile increases with the reinforcement ratio and buried depth increasing, and decreases with the axial compression ratio of pile top increasing. Meanwhile, the displacement ductility coefficient also increases with the buried depth of PHC pile increasing, but does not show significant influence by the reinforcement ratio and shear strength of undrained soil. The results can provide some reference for the seismic design of PHC pipe piles.

\section{Introduction}

For its high strength, fast construction, and low cost, PHC pipe piles are widely used in the high-piled wharf structure. However, there is also lack of the knowledge about the seismic performance of the PHC pile-supported wharf considering soil-pile interaction. Several western researchers have carried out some research on the seismic performance of PHC pipe piles earlier. Applying the cyclic reciprocating loading test on the prestressed hollow precast pile, Budek et al. [1] studied the influence of the stirrup ratio of pile body, external constraints, and non prestressed longitudinal reinforcement on displacement ductility and bending resistance of the pile foundation. Roeder et al. [2] compared the seismic performance of two different forms of joints by applying cyclic reciprocating tests on the joints of prestressed concrete piles and pedestals. The seismic performance of PHC pipe piles under horizontal force also attract some Chinese engineering staff's attention after the accident of Lotus Riverside Building in Shanghai in 2009 [3]. Xian et al. [4] assume that the bottom of pile is fixed, and the quasi-static test of the PHC pipe pile was carried out. The effect of improvements, including adding steel fiber, core-filled concrete, and non-prestressing reinforcement on the ductility, bearing capacity, energy dissipation of the PHC pile were discussed, respectively. Han [5] also applied the cyclic reciprocating loading on the reinforced concrete pile groups in a sandy soil box. The effects of the free length of pile and water content of sandy soil on the hysteresis curve, skeleton curve, and displacement ductility coefficient was been investigated. In the present study, the parameters of the PHC pipe pile listed in literature [6] are used to investigate the effects of soil around piles on the seismic performance of the pile. According to the earlier report [7], the p-y curve of soft clay under cyclic loading is used to simulate the soil-pile interaction under earthquake. The dissipating hysteretic energy and displacement ductility of PHC pipe piles is studied by the numerical simulation. The results can provide some reference for the seismic design of PHC pipe piles.

\section{Numerical Analysis Method}

Fibrous Beam Element Model. The B21 beam element in ABAQUS software is used to simulate the PHC pipe pile, and thick pipe was chosen for the cross section of the beam element. For reflecting the 
concrete cover layer and the concrete core confronted by the stirrups, the common node method was used and the beam elements representing the concrete cover layer and the concrete core between the two nodes were established. Thus, the displacements of the two beam elements are the same, and the deformation between the concrete cover and the concrete core are compatible. Using the rebar keyword, on the section of the beam element section, the steel reinforcement is inserted on the position of the prestressed steel reinforcement in the concrete core. The initial tensile stress is applied to the longitudinal reinforcement of the pipe pile through the keyword of initial condition. The initial tensile stress of the prestressed reinforcement considering the loss of the prestress is calculated according to the GB13476-2009 [8]. The division of the fibrous point and the prestressed reinforcement on the cross section of the beam are shown in Fig. 1.

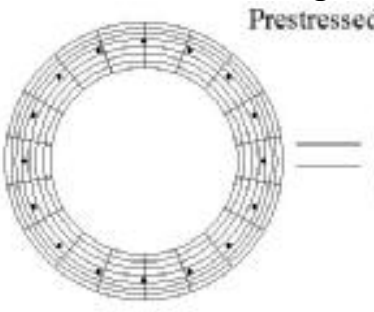

(a)

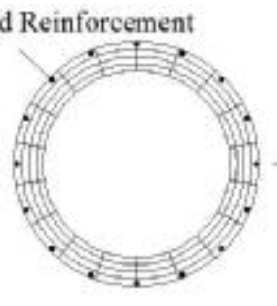

(b)

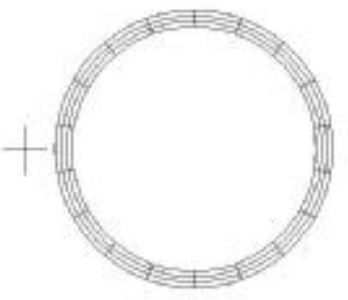

(c)

Fig.1. Division of fibrous point and prestressed reinforcement on the cross section of beam, (a) PHC pipe pile; (b) concrete core; (c) concrete cover

Material Constituents and Parameters. The UCONCRETE01 and USTEEL02 constitutive mode in the pq-fiber subroutine were used for the concrete constitutive and the prestressed longitudinal reinforcement constitutive, respectively [9]. In addition, the residual strain $\varepsilon_{\text {res }}$ of concrete is calculated through the method reported in literature [10]. The double broken line model, which proposed by CLOUGH [11], is used in the reinforcement constitutive.

The concrete of $\mathrm{PHC}$ pipe piles is $\mathrm{C} 80$ grade. The deformed bar with tensile strength no less than $1420 \mathrm{MPa}$ and ductility grade 35 is used as the prestressed reinforcements, which are evenly distributed along the cross section of the pile. The elastic modulus $E_{0}$, yield strength $f_{y}$, and hardening stiffness coefficient of the prestressed reinforcement are $200 \mathrm{GPa}, 1420 \mathrm{MPa}$, and 0.001 , respectively. The parameters of the concrete cover layer and the concrete core are calculated according to the Mander constitutive model [12].

Simulation of Pile-soil Interaction. In the present study, the pile-soil interaction in the horizontal direction was simulated by the model of p-y spring in soft clay soil under cyclic loading [7]. In that, the function of $\mathrm{p}-\mathrm{y}$ spring is achieved by connector connection unit. The springs are arranged every $0.5 \mathrm{~m}$ below the mud surface. One end of the spring is connected to the pile and the other end is fixed. In the high pile wharf, the rotational freedom of the pile top is limited by the cap, and vertical freedom of the pile bottom is also limited by the bearing stratum. Therefore, the axial pressure is applied by the vertical concentrated force on the pile top, and the horizontal earthquake load is applied by the horizontal displacement on the pile top. The calculation diagram of PHC piles is shown in Fig. 2 .

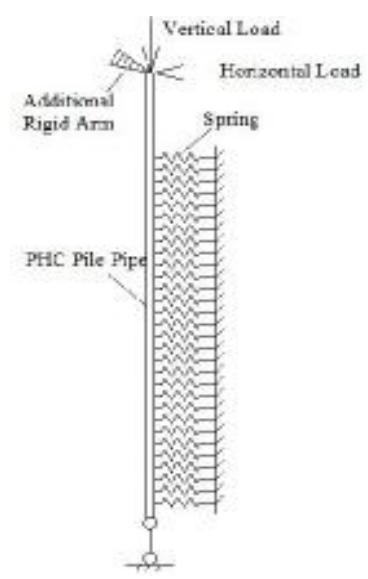

Fig.2. The calculation diagram of PHC piles 


\section{Calculation Results and Discussion}

Parameters. As mentioned in reference [6], the PHC piles, with a length of $25 \mathrm{~m}$ and an outside diameter of $800 \mathrm{~mm}$, are stuied. The parameters of the PHC piles are shown in Tab.1. In order to investigate the influence of reinforcement ratio, axial compression ratio, and buried depth on the seismic performance of the pile foundation, 11 kinds of conditions in Tab.2 are selected.

Tab.1. Parameters of PHC piles

\begin{tabular}{ccccccccc}
\hline Model & $\begin{array}{c}\text { Diameter of } \\
\text { PHC Piles } \\
(\mathrm{mm})\end{array}$ & $\begin{array}{c}\text { Thickness } \\
(\mathrm{mm})\end{array}$ & $\begin{array}{c}\text { Stirnup } \\
\text { Spacing } \\
(\mathrm{mm})\end{array}$ & $\begin{array}{c}\text { Diameter } \\
\text { of Stirnup } \\
(\mathrm{mm})\end{array}$ & $\begin{array}{c}\text { Prestressed } \\
\text { Reinforcement }\end{array}$ & $\begin{array}{c}\text { Reinforcement } \\
\text { Ratio } \\
(\%)\end{array}$ & $\begin{array}{c}\text { Diameter of } \\
\text { Prestressed } \\
\text { Reinforcement } \\
\text { Distribution Circle } \\
(\mathrm{mm})\end{array}$ & $\begin{array}{c}\text { Effective } \\
\text { Preloading } \\
\text { Stress of } \\
\text { Concrete } \\
(\mathrm{MPa})\end{array}$ \\
\hline $\mathrm{A}$ & 800 & 130 & 80 & 6 & $16 \Phi 10.7$ & 0.53 & 690 & 4.57 \\
$\mathrm{AB}$ & 800 & 130 & 80 & 6 & $16 \Phi 12.6$ & 0.73 & 690 & 6.16 \\
$\mathrm{~B}$ & 800 & 130 & 80 & 6 & $32 \Phi 10.7$ & 1.05 & 690 & 8.47 \\
$\mathrm{C}$ & 800 & 130 & 80 & 6 & $32 \Phi 12.6$ & 1.46 & 690 & 11.1 \\
\hline
\end{tabular}

Tab.2. Calculation conditions

\begin{tabular}{ccccc}
\hline Condition & $\begin{array}{c}\text { Reinforcement } \\
\text { Ratio } \\
(\%)\end{array}$ & $\begin{array}{c}\text { Axial Compression } \\
\text { Ratio }\end{array}$ & $\begin{array}{c}\text { Depth of Pile } \\
\text { Foundation in Soil } \\
(\mathrm{m})\end{array}$ & $\begin{array}{c}\text { Undrained Shear } \\
\text { Strength of Soil } \\
(\mathrm{MPa})\end{array}$ \\
\hline 1 & 0.53 & 0.1 & 20 & 20 \\
2 & 0.73 & 0.1 & 20 & 20 \\
3 & 1.05 & 0.1 & 20 & 20 \\
4 & 1.46 & 0.1 & 20 & 20 \\
5 & 1.46 & 0.1 & 17 & 20 \\
6 & 1.46 & 0.1 & 23 & 20 \\
7 & 1.46 & 0.2 & 20 & 20 \\
8 & 1.46 & 0.4 & 20 & 20 \\
9 & 1.46 & 0.1 & 20 & 40 \\
10 & 1.46 & 0.1 & 20 & 60 \\
11 & 1.46 & 0.1 & 20 & 80 \\
\hline
\end{tabular}

Loading Mode. As the earlier study [13] reported, the displacement-control mode is adopted in the present study. During the applied displacement process, when the horizontal bearing capacity of the the pile top is being reduced to $85 \%$ of the maximum value, the loading is stopped. In calculation, the horizontal bearing capacity of the pile top, which is corresponding to each grade of displacement load, is determined by measuring the horizontal force of the pile top.

Results and Discussion. The influence of reinforcement ratio, axial compression ratio, buried depth, and shear strength of undrained soil on the seismic performance of the PHC pipe piles is studied. The selected conditions are shown in Tab.2. The analysis of displacement ductility and cumulative hysteretic energy dissipation is as follows.

The yielded state of the prestressed reinforcement in the PHC pipe pile was taken as the pile yield state of the pile foundation, and the load value of the skeleton curve being reduced to $85 \%$ of the maximum load was taken as the ultimate failure state of the pile foundation [14]. The variation of displacement ductility coefficient under different factors is shown in Fig.3.

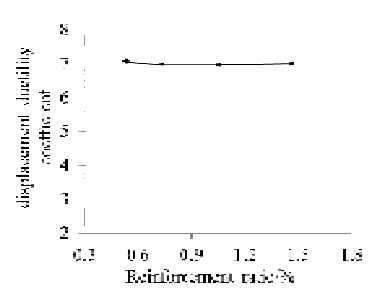

(a)

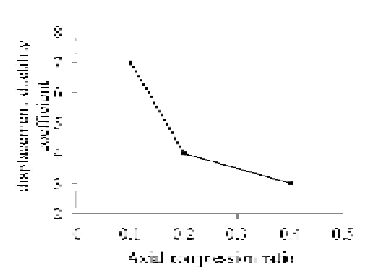

(b)

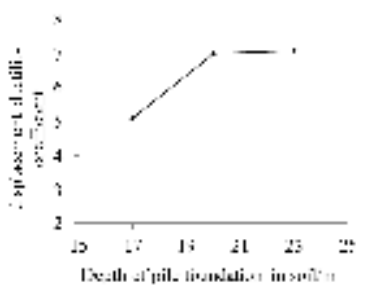

(c)

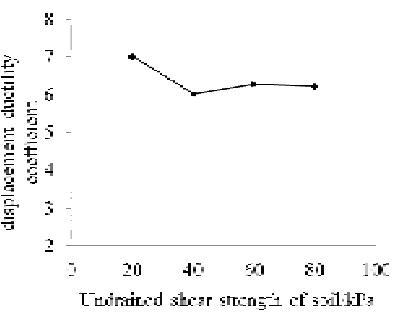

(d)

Fig.3. Effect of (a) reinforcement ratio; (b) axial compression ratio; (c) buried depth; (d) undrained shear strength of soil on displacement ductility coefficient of the pile foundation 
As Fig.3 (a) shows, the displacement ductility of the PHC pipe piles do not show significantly influence by the reinforcement ratio. When the axial compression ratio is 0.1 and the buried depth is 20 $\mathrm{m}$, the values of the displacement ductility coefficients of the four PHC pipe piles are around 7.0. As the results shown in Fig.3 (b), the displacement ductility coefficient of the pile is obviously reduced with increasing axial compression ratio of the pile top. For the PHC pipe pile with the buried depth of $20 \mathrm{~m}$ and the pile type $\mathrm{C}$, the displacement ductility coefficient is increased by $132.5 \%$ as the axial compression ratio of the pile top was reduced from 0.4 to 0.1. As Fig.3 (c) shows, as the buried depth of the pile increasing, the value of the displacement ductility coefficient also increases. For the type $\mathrm{C}$ PHC pipe pile with axial compression ratio of 0.1 , the displacement ductility coefficient increased by $39.8 \%$ when the buried depth increased from 17 to $23 \mathrm{~m}$. With the increase of the undrained shear strength of soil, the yield displacement and ultimate displacement of the pile foundation were gradually reduced. Thus, the displacement ductility coefficient of the pile foundation was slightly influenced by the undrained shear strength. As the results shown in Fig.3 (d), the displacement ductility coefficient of the pile changes from 6.0 to 7.0 when the undrained shear strength of soil increases from $20 \mathrm{kPa}$ to 80 $\mathrm{kPa}$.

Hysteresis energy consumption is the area surrounded by the hysteresis curve, which related with the energy dissipation of the component in the earthquake. The higher hysteresis energy consumption means better seismic performance. The cumulative hysteretic energy dissipation of pile foundations under different conditions are presented in Fig.4. As Fig.4 (a) and Fig.4 (c) shows, the cumulative hysteresis energy significantly increased with the reinforcement ratio and buried depth. When the axial pressure is 0.1 and the buried depth is $20 \mathrm{~m}$, comparing with the pile with the reinforcement ratio of $0.53 \%$, the cumulative hysteresis energy increased by $59.9 \%$ and $122.6 \%$ for the samples with the reinforcement ratio of $1.05 \%$ and $1.46 \%$, respectively. As Fig.4 (c) shows, for the PHC pipe pile with the axial compression ratio of 0.1 and the reinforcement ratio of 1.46 , the cumulative hysteretic energy dissipation increased by 57.5\% when the buried depth increases from 17 to $23 \mathrm{~m}$. On the contrary, the cumulative hysteretic energy significantly decreases with the axial compression ratio, as shown in Fig. 4 (b). For the PHC pipe pile with the buried depth of $20 \mathrm{~m}$ and the reinforcement ratio of $1.46 \%$, the cumulative hysteresis energy dissipation with the axial compression ratio of 0.1 increased by $207.3 \%$ compared to the one with the axial compression ratio of 0.4. As Fig.4 (d) shows, the cumulative hysteretic energy dissipation of pile foundation does not show significant influence by undrained shear strength of soil.

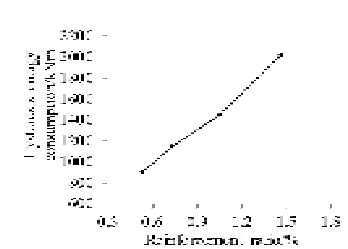

(a)

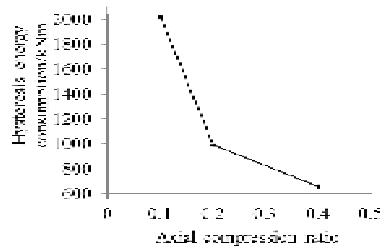

(b)

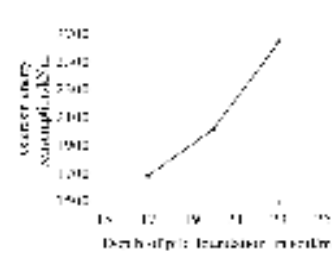

(c)

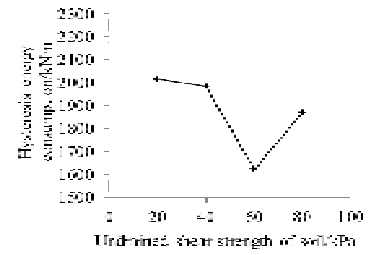

(d)

Fig.4. Effect of (a) reinforcement ratio; (b) axial compression ratio; (c) buried depth; (d) undrained shear strength of soil on hysteresis energy consumption

Overall, the hysteretic energy consumption of PHC pipe piles foundation increased with the reinforcement ratio and the penetration depth, and decreased with the axial compression ratio, but is not significantly influenced by the shear strength of undrained soil.

\section{Conclusion}

The influence of the reinforcement ratio, the buried depth, the axial compression ratio, and the shear strength of undrained soil on the seismic performance of PHC pipe piles was studied by cyclic loading. The results show that the reinforcement ratio does not show significant influence on the displacement ductility coefficient of PHC pipe piles, but show obvious influence on the cumulative hysteretic energy dissipation of the pile. The cumulative hysteretic energy dissipation increases with the reinforcement 
ratio increasing. With the increase of the burid depth of PHC piles or decrease of the axial compression ratio of pile top, both the displacement ductility coefficient and cumulative hysteresis energy dissipation of the pile increases obviously. On the other hand, the shear strength of undrained soil presents little effect on the displacement ductility coefficient and the cumulative hysteretic energy dissipation of PHC pipe piles.

\section{Acknowledgements}

The work described in this paper was supported by the Natural Science Foundation of Jiangsu Province (BK20151498).

\section{References}

[1] Budek A M, Priestleym J N. Experimental analysis of flexural hinging in hollow marine prestressed pile shafts [J]. Coastal Engineering Journal, 2005, 47(1): 1 20.

[2] Roeder C, Graff R, Soderstrom J, and Yoo J, Seismic performance of pile-wharf connections [J]. Journal of Structural Engineering, 2005, 131(3), 428 437.

[3] Jieren Song. Analysis on the Causes of the Overturning of Building 7 in District near Lianhua River, Shanghai [J]. Architecture Technology, 2010, (09): 843-846. (In Chinese)

[4] Xian Rong, Xuyue Wang, Yanyan Li. Experimental study on seismic behavior of improved PHC pipe pile under repeated loading [J]. Journal of Building Science, 2013,07: 59-65. (In Chinese)

[5] Zhenfeng Han, Aijun Ye. Study on Seismic Behavior of Bridge Pile Foundation [J]. Journal of Hefei University of Technology (Natural Science Edition), 2016,02: 199-204 + 216. (In Chinese)

[6] 10G409, Prestressed Concrete Pipe Pile [S]. Beijing: China Planning Press, 2010. (In Chinese)

[7] API RP 2A-WSD-2005, Recommended practice for planning, designing and constructing fixed offshore platforms-working stress design [S].

[8] GB13476-2009, Pre-tensioned Prestressed Concrete Pipe Pile [S]. Beijing: China Standard Press, 2010. (In Chinese)

[9] Tsinghua University Civil Engineering Department of Structural Engineering .PQ-Fiber User Manual v1.6 [P]. (In Chinese)

[10] Hognestad E. A study of combined bending and axial load in reinforced concrete members [D].Urbara: University of Illinois Engineering Experiment Station, 1951.

[11]CLOUGH, R W. Effect of stiffness degradation on earthquake ductility requirements [M]. SESM66-16. Berkeley: Department of Civil Engineering, University of California, Berkeley,1966.

[12]Port of Long Beach, Wharf Design Criteria [S]. Version3.0. Long Beach: CA, 2012.

[13]Zhijian Yang. Research on seismic performance of prestressed high strength concrete pile [D]. Tianjing University, 2014. (In Chinese)

[14]JGJ101-96, Specificating of testing methods for earthquake resistant building [S]. 1996. (In Chinese) 